\title{
HISTOCHEMICAL STAINING OF ORBICULARIS OCULI MUSCLE IN ECTROPION AND ENTROPION
}

\author{
RUTH M. MANNERS ${ }^{1}$ and ROY O. WELLER ${ }^{2}$ \\ Southampton
}

\begin{abstract}
SUMMARY
A histochemical study of orbicularis oculi was undertaken to test the hypothesis that there is a difference in the percentage and size of muscle fibre types which accounts for the development of involutional ectropion or entropion. Wedge excisions from lower lids of patients undergoing repair of these conditions were frozen-sectioned and stained histochemically to reveal muscle fibre types. Five ectropion and five entropion specimens were obtained, and the percentage of type 1 and type 2 fibres, fibre perimeters and fibre diameters were measured. An abundance of type 2 fibres was found in both ectropion (mean 89.6\%) and entropion (mean 82.6\%). No significant difference was found with respect to fibre type, perimeter or diameter when ectropion was compared with entropion or when either was compared with normals. Type 2 fibres were larger than type 1 in both ectropion and entropion. We conclude that no significant difference could be identified between orbicularis muscle fibres in ectropion, entropion and normals to account for the development of the eyelid malpositions.
\end{abstract}

Involutional ectropion and entropion are lower lid malpositions with significant morbidity including visual impairment. In these conditions there are morphological and functional changes in the eyelids and the cause appears to be multifactorial. ${ }^{1-6}$ Two previous studies have considered the histopathological changes in these disorders: Stefanyznyn et $\boldsymbol{a l}^{7}{ }^{7}$ studied specimens from lids with ectropion and Sisler et $a l .^{2}$ compared ectropion with entropion specimens. Both studies looked at the tarsal plate and orbicularis oculi in formalin-fixed specimens and used HBFP stain ${ }^{8}$ which identified ischaemic changes in the muscle - greater in entropion than ectropion. ${ }^{3}$

The following study was undertaken to examine in greater detail the orbicularis oculi muscle in ectropion and entropion using histochemical staining of cryostat sections. This has several advantages over formalin-fixed specimens previously used:

From: 'The Eye Unit, Southampton, UK: 'Department of Neurosciences, University of Southampton, Southampton General Hospital, Southampton, UK.

Correspondence to: Miss R. M. Manners, FRCOphth, The Eye Unit, Southampton General Hospital, Southampton SOI6 6YD, UK.
1. Normal tissue architecture is preserved and true muscle fibre size can be measured.

2. Muscle fibre types are distinguished by the stains: type 1 (slow, sustained) and type 2 (fast, twitch) fibres. Selective involvement of fibre type can be identified.

3. Structural changes in muscle which are associated with enzyme abnormalities can be detected.

\section{MATERIALS AND METHODS}

A total of five specimens were obtained from patients with ectropion who were undergoing full-thickness, wedge excision from the lower lid, and five specimens from patients with entropion who were undergoing Quickert's procedure (transverse lid split, everting sutures and horizontal lid shortening). ${ }^{9}$ None of the patients had undergone previous lid surgery. All procedures were carried out under local anaesthetic. Patients were assessed clinically for the following features: lower lid laxity, medial and lateral canthal tendon laxity and skin laxity. These were graded on a scale from 0 to 3 . Any globe or lid disorders were also documented.

The wedges of lid were frozen in liquid nitrogen. Each specimen was bisected perpendicular to the lid margin and mounted on a standard chuck, cut surface uppermost. Sec-

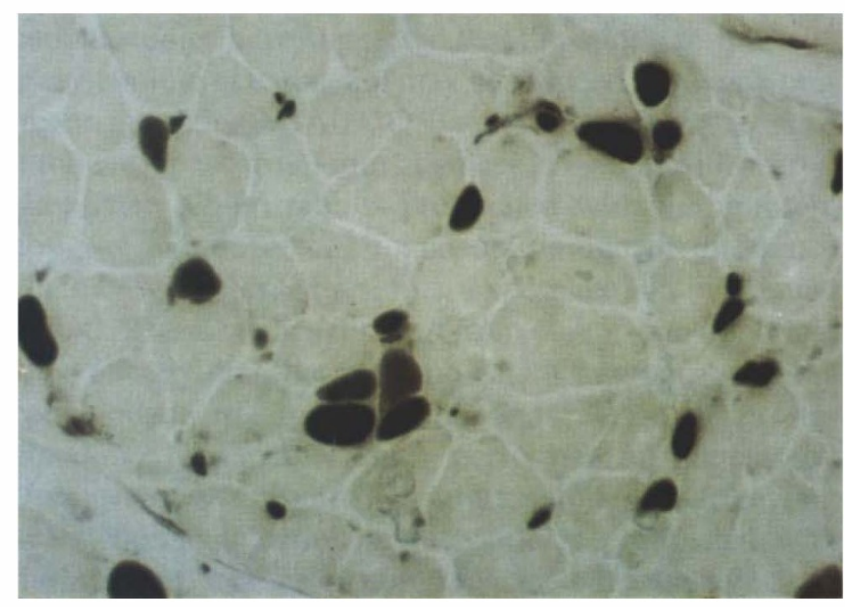

Fig. 1. ATPase stain at pH 4.2 of orbicularis oculi muscle showing dark type 1 fibres and pale type 2 fibres. 
Table I. Repeated trials of measurement of the perimeters of six muscle fibres to assess the reproducibility of measurement

\begin{tabular}{lccccccc}
\hline Trial & Fibre 1 & Fibre 2 & Fibre 3 & Fibre 4 & Fibre 5 & Fibre 6 & Mean \\
\hline 1 & 123.8 & 113.0 & 80.4 & 63.0 & 114.3 & 494.5 & 164.8 \\
2 & 121.5 & 116.8 & 82.2 & 60.7 & 112.0 & 493.3 & 164.4 \\
3 & 114.1 & 117.0 & 86.7 & 60.9 & 111.1 & 489.9 & 163.3 \\
4 & 121.7 & 115.5 & 78.4 & 65.5 & 112.5 & 493.6 & 164.5 \\
Mean & 120.3 & 115.6 & 81.9 & 62.5 & 112.5 & 492.8 & 164.3 \\
SD & 4.2 & 1.8 & 3.6 & 2.2 & 1.4 & 2.0 & 0.7 \\
Coefficient of variation & 3.5 & 1.6 & 4.3 & 3.6 & 1.2 & 0.4 & 0.4 \\
\hline
\end{tabular}

tions, $8 \mu \mathrm{m}$ thick, were cut and mounted directly on to slides. The following histological stains were used: haematoxylin and eosin, reticulin to detect fibrous change, and oil-red-O to detect excessive lipid deposition. The following histochemical stains were used: NADH, SDH and ATPase at pH 9.4, 4.6 and 4.2.

The proportion of type 1 to type 2 fibres and the size of the pretarsal muscle fibres were measured with a computer program using specimens stained with ATPase at $\mathrm{pH} 4.2$ (Fig. 1) which gave the most reliable differentiation between type 1 and type 2 fibres. Magnification was $\times 25$. The following three measurements were taken for every complete type 1 and type 2 muscle fibre contained within one viewing field:

1. Number: to assess the percentage of type 1 and type 2 fibres.

2. Perimeter: as a measurement of fibre size.

3. Diameter: found by defining the longest diameter (the 'major axis') and measuring the greatest diameter perpendicular to this (the 'minor axis'). The minor axis is considered to be the measurement least likely to be affected by imperfect transverse sectioning. ${ }^{10}$

The measurements were repeated for three separate viewing fields and the mean of the results calculated.

\section{Reproducibility}

Reproducibility of results was checked by measuring the perimeters of six adjacent fibres on four separate occasions (Table I). The $95 \%$ confidence limits were calculated using the equation:"

Table II. Results of clinical examination of the ocular structures

\begin{tabular}{|c|c|c|c|c|c|}
\hline Sex & $\begin{array}{l}\text { Age } \\
(\mathrm{yr})\end{array}$ & $\begin{array}{c}\text { Lower } \\
\text { lid } \\
\text { laxity }\end{array}$ & $\begin{array}{l}\text { Canthal } \\
\text { tendon } \\
\text { laxity }\end{array}$ & $\begin{array}{c}\text { Skin } \\
\text { ageing } \\
\text { changes }\end{array}$ & $\begin{array}{l}\text { Globe/lid } \\
\text { disorders }\end{array}$ \\
\hline \multicolumn{6}{|c|}{ Ectropion } \\
\hline M & 91 & ++ & - & ++ & Ptosis, symblepharon \\
\hline M & 88 & + & - & ++ & - \\
\hline M & 86 & + & - & ++ & Blepharitis, ECCE \\
\hline M & 84 & +++ & - & + & - \\
\hline M & 76 & + & - & + & Lagophthalmos \\
\hline \multicolumn{6}{|c|}{ Entropion } \\
\hline $\mathrm{F}$ & 73 & + & - & - & - \\
\hline $\mathrm{F}$ & 79 & +++ & - & - & - \\
\hline $\mathrm{F}$ & 73 & ++ & - & + & - \\
\hline M & 78 & + & - & - & - \\
\hline M & 68 & ++ & - & - & POAG \\
\hline
\end{tabular}

Key, -, absent; +, mild; ++, moderate; +++, severe.

ECCE, extracapsular cataract extraction: POAG, primary open angle glaucoma.

$$
95 \% \text { confidence limits }=\text { mean } \pm t\left(s / \mathrm{V}_{n}\right)
$$

where $t$ is the value from the $t$-distribution table corresponding to the $95 \%$ confidence level and 3 degrees of freedom $(=3.182), s$ is the standard deviation $(=0.67)$ and $n$ is the sample size $(=4)$. Thus:

$$
95 \% \text { confidence limits }=164.3 \pm 1.07( \pm 0.6 \%)
$$

\section{RESULTS}

\section{Clinical Features}

Age, sex and clinical findings are shown in Table II. The average age of patients with ectropion was 85 years and with entropion, 74.2 years. Lid laxity ranged from mild (grade 1 ) to severe (grade 3 ) in both conditions. There was no significant canthal tendon laxity. Patients with ectropion had more skin laxity than was apparent in patients with entropion.

\section{Histology}

Microscopic examination of specimens stained histologically did not show any abnormal degree of fibrous tissue or lipid deposition.

\section{Muscle Fibre Type}

In orbicularis oculi the few type 1 fibres were interspersed in a sea of type 2 fibres (Fig. 2), which accords with previously published data from post-mortem specimens from patients without lid abnormalities ( 5 males, average age 21.83 years). ${ }^{12}$ Most other striated muscles show the type

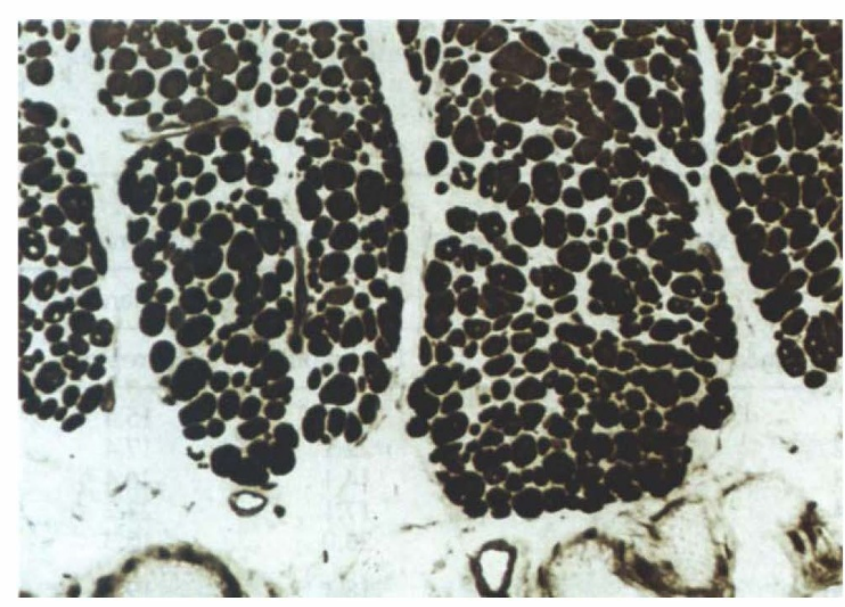

Fig. 2. ATPase stain at $p H 9.4$ of orbicularis oculi showing a sea of dark type 2 fibres with very few pale type 1 fibres scattered throughout. 


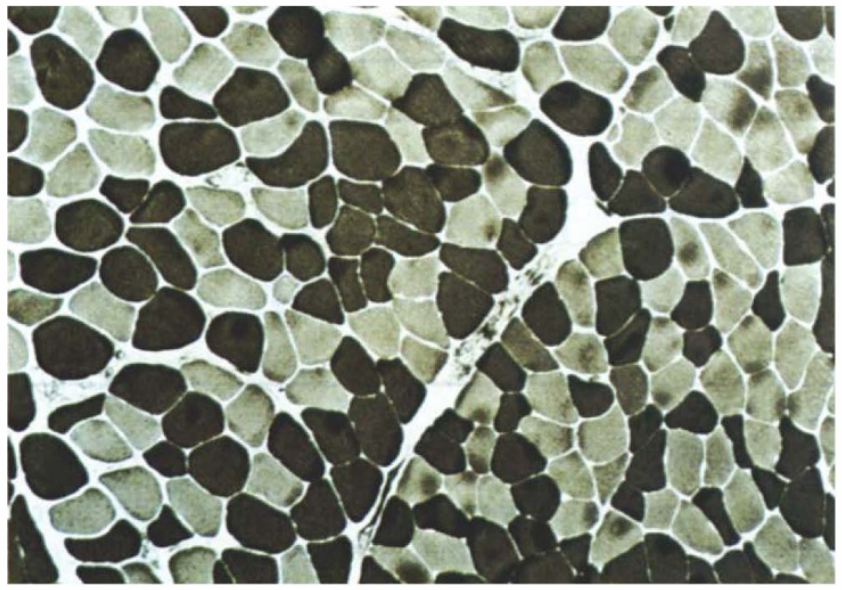

Fig. 3. ATPase stain at pH 9.4 of rectus femoris muscle showing a chequerboard effect of type 1 and type 2 fibres.

1 and 2 fibres distributed throughout in a chequerboard fashion (Fig. 3). The collated results of percentages of muscle fibre type are shown in Table III. There was no statistically significant difference found in fibre type percentages (using the Wilcoxon signed rank test where $p=0.05$ as the level of statistical significance) when comparing ectropion with entropion or when comparing ectropion or entropion with previously published data for normals. ${ }^{12}$

\section{Muscle Fibre Perimeter}

The results of measurement of type 1 and type 2 fibre perimeters in ectropion and entropion are shown in Table IV. There was no statistically significant difference when
Table III. Proportions of type 1 fibres in ectropion and entropion

\begin{tabular}{lccc}
\hline & \multicolumn{3}{c}{ \% type 1 fibres } \\
\cline { 2 - 4 } Specimen & Ectropion & Entropion & Normals $^{\mathrm{a}}$ \\
\hline 1 & 8.9 & 9.3 & 21.0 \\
2 & 5.1 & 36.7 & 14.0 \\
3 & 9.6 & 23.5 & 23.5 \\
4 & 25.4 & 7.7 & 18.0 \\
5 & 7.8 & 18.6 & 0.5 \\
Mean & 11.4 & 19.2 & 15.4 \\
$95 \%$ confidence limits & $1.4-21.4$ & $4.6-33.8$ & $4.1-26.7$ \\
\hline
\end{tabular}

"Data taken from Johnson et al."2

comparing type 1 and type 2 fibres between ectropion and entropion. Type 2 fibre perimeters were not significantly greater than type 1 in either ectropion or entropion.

\section{Muscle Fibre Diameter}

The results of 'minor axis' measurements are shown in Table V compared with previously published data from post-mortem specimens. ${ }^{13}$ Both fibre types showed no statistically significant difference when comparing diameter between ectropion and entropion. The diameters of type 2 fibre were not significantly larger than type 1 in either condition.

\section{DISCUSSION}

The present study has demonstrated the use of histochemical examination of the orbicularis muscle in surgically excised lid specimens from patients with ectropion and entropion. The lack of normal controls is due to the obvious difficulty in obtaining specimens from subjects with

Table IV. Mean perimeters of type 1 and type 2 muscle fibres in ectropion and entropion

\begin{tabular}{|c|c|c|c|c|}
\hline \multirow[b]{3}{*}{ Specimen } & \multicolumn{4}{|c|}{ Fibre perimeter $(\mu \mathrm{m})$} \\
\hline & \multicolumn{2}{|c|}{ Type 1 fibres } & \multicolumn{2}{|c|}{ Type 2 fibres } \\
\hline & Ectropion & Entropion & Ectropion & Entropion \\
\hline 1 & 64.3 & 76.5 & 116.2 & 96.1 \\
\hline 2 & 83.8 & 66.0 & 108.9 & 142.2 \\
\hline 3 & 40.3 & 111.4 & 89.7 & 143.4 \\
\hline 5 & 101.8 & 83.4 & 134.9 & 127.3 \\
\hline Mean & 72.3 & 86.8 & 116.4 & 124.1 \\
\hline $\mathrm{SD}$ & 20.5 & 15.8 & 28.3 & 18.2 \\
\hline $95 \%$ confidence limits & $63.1-81.5$ & 79.7-93.9 & $103.7-129.1$ & $115.0-132.2$ \\
\hline
\end{tabular}

Table V. Mean 'diameter' of type 1 and type 2 fibres for ectropion and entropion specimens compared with non-age-matched controls

\begin{tabular}{|c|c|c|c|c|c|c|}
\hline \multirow[b]{2}{*}{ Specimen } & \multicolumn{3}{|c|}{ Type 1 fibres $(\mu \mathrm{m})$} & \multicolumn{3}{|c|}{ Type 2 fibres $(\mu \mathrm{m})$} \\
\hline & Ectropion & Entropion & Normals ${ }^{a}$ & Ectropion & Entropion & Normals ${ }^{a}$ \\
\hline 2 & 22.1 & 17.4 & - & 22.6 & 31.4 & - \\
\hline 3 & 14.1 & 26.4 & - & 20.4 & 32.7 & - \\
\hline 4 & 17.1 & 23.2 & - & 26.3 & 37.0 & - \\
\hline 5 & 23.0 & 15.3 & - & 27.5 & 23.7 & - \\
\hline Mean & 18.1 & 19.5 & 21.7 & 24.5 & 29.9 & 24.2 \\
\hline SD & 2.2 & 4.5 & - & 6.6 & 5.0 & - \\
\hline $95 \%$ confidence limits & $17.1-19.1$ & $17.5-21.5$ & $11-31$ & $21.5-27.5$ & $27.7-32.1$ & $14-35$ \\
\hline
\end{tabular}

a Data taken from Polgar et al. ${ }^{13}$ 
normal lower eyelids. Control measurements of fibre type and diameter were therefore obtained (with permission) from previously published data on post-mortem specimens. ${ }^{12,13}$

The high percentage of type 2 fibres in ectropion (mean $89.6 \%$ ) and entropion (mean $82.6 \%$ ) confirmed previous findings that orbicularis oculi contains a higher proportion of type 2 fibres ${ }^{14}$ than do other facial muscles. ${ }^{15}$ Type 2 are fast twitch fibres and their predominance in pre-tarsal orbicularis corresponds with its 'phasic' action of rapid blinking. Because all our patients presented with some degree of lid laxity, it was expected that the proportion of type 1 'tonic' fibres would be reduced. However, there was no significant difference between fibre percentages found in entropion, ectropion and young normals. The reference range in normal individuals reported by Johnson et al. $^{12}$ is large (as shown by the $95 \%$ confidence limits) from a small number of specimens (five). The numbers in our study were also small and thus any change would need to be marked to be significant.

It is known that adult muscle fibre sizes are reached by 15 years of age, ${ }^{16}$ but the normal involutional changes in the muscle fibres are unknown and further work is required to elucidate these. Happak et al. ${ }^{15}$ studied mimic muscles and found orbicularis oculi to contain the smallest fibres. Our study found a similar fibre diameter range. Measurement of mean fibre perimeter and mean diameter showed no significant difference for either fibre type between entropion and ectropion. Type 2 fibre perimeters and diameters were found to be larger than type 1 in all specimens but this did not achieve statistical significance. Polgar et al. $^{13}$ noted a similar finding in orbicularis oculi. In their study of 50 muscle sites, they were unable to correlate the relative sizes of type 1 and type 2 fibres with the function of the muscle.

In this study we sought to demonstrate a difference in percentage and size of orbicularis muscle fibre types to account for the development of involutional ectropion or entropion. Although the numbers were small, our results do not support the hypothesis that changes in muscle fibres contribute to these diseases.

We would like to thank Judy Mepham and Phil Steart for their help in specimen preparation.
Key words: Ectropion, Entropion, Histochemical staining, Muscle fibre types, Orbicularis oculi.

\section{REFERENCES}

1. Dalgleish R, Smith JLS. Mechanics and histology of senile entropion. Br J Ophthalmol 1966;50:79-91.

2. Sisler HA, Labay GR, Finlay JR. Senile ectropion and entropion: a comparative histopathological study. Ann Ophthalmol 1976;8:319-22.

3. Dryden RM, Leibsohn J, Wobig J. Senile entropion: pathogenesis and treatment. Arch Ophthalmol 1978;96:1883-5.

4. Putterman AM. Ectropion of the lower eyelid secondary to Muller's muscle capsulopalpebral head detachment. Am J Ophthalmol 1978;85:814-7.

5. Jones LT. The anatomy of the lower eyelid and its relation to the cause and cure of entropion. Am J Ophthalmol 1960;49: $29-36$.

6. Collin JRO, Rathbun JE. Involutional entropion: a review with evaluation of a procedure. Arch Ophthalmol 1978;96: 1058-67.

7. Stefanyszyn MA, Hidayat A, Flanagan JC. The histopathology of involutional ectropion. Ophthalmology 1985;92: $120-8$.

8. Schere AT, Masi AT. Technical aspects of the HBFP stain applied to skeletal muscle. Histochem J 1975;7:335-41.

9. Collin JRO. A manual of systematic eyelid surgery, 2nd ed. Edinburgh: Churchill Livingstone, 1989.

10. Song SK, Shimada N, Anderson PJ. Orthogonal diameter in the analysis of muscle fibre size and form. Nature 1963;200: 1220-1.

11. Armitage P, Berry G. Statistical methods in medical research. 2nd ed. Oxford: Blackwell Scientific, 1987.

12. Johnson MA, Polgar J, Weightman D, Appleton D. Data on the distribution of fibre types in thirty-six human muscles: an autopsy study. J Neurol Sci 1973;18:111-29.

13. Polgar J, Johnson MA, Weightman D, Appleton D. Data on fibre size in thirty-six human muscles: an autopsy study. J Neurol Sci 1973;19:307-18.

14. Edstrom L, Kugelberg E. Histochemical composition, distribution of fibres and fatiguability of single motor units. J Neurol, Neurosurg Psychiatry 1968;31:424-33.

15. Happak W, Burggasser G, Gruber H. Histochemical characteristics of human mimic muscles. J Neurol Sci 1988;83: 25-35.

16. Brooke MH, Engel WK. The histographic analysis of human muscle biopsies with regard to fibre types. I. Adult male and female. Neurology (Minneapolis) 1969;19:221-33. 